\title{
Using a Common Device to Introduce First-Year Students to Various Engineering Technology Disciplines
}

\author{
Scott Segalewitz \\ University of Dayton
}

\begin{abstract}
The University of Dayton engineering technology first-year seminar provides students with an effective introduction to engineering technology principles and practices. Facilitated by the department chair, students in each of the department's five majors plus those entering the department as "undeclared" experience tools necessary for success in a technical curriculum.

One four-class module uses a common device, the switch, to introduce students to various engineering fields. In a hands-on approach, students test, design, disassemble, analyze, and reassemble switches while learning about programs of study, the interaction between disciplines, and possible career paths. Using this device, student teams are introduced to electronics by discovering how various switches operate, and by designing a process to test the electrical connections. To introduce mechanical design, teams are given a problem that requires the use of a switch. They spend some time brainstorming ideas for their design, and produce a concept drawing, including the mechanical details for their team's device. The manufacturing process is introduced by giving each team an identical $120 \mathrm{Vac}$ switch, and asking them to carefully disassemble it and create detailed assembly drawings and a bill of materials. They then need to use their own assembly drawings to reassemble the switches. During this process, students are exposed to the various materials of each component and the processes involved in manufacturing each part. Finally, students are introduced to industrial engineering concepts by using their assembly drawings from the previous week to design efficient processes to assemble multiple switches, learn about basic economic and efficiency principles, and investigate quality assurance issues.

While students are learning about engineering disciplines, other course and TC2K outcomes are also realized. All four sections involve critical thinking concepts and interdisciplinary student teams. Creativity in design is seen in the mechanical and industrial sections, and the mechanical and electronic sections require students to make brief technical presentations. Overall, students report a high degree of satisfaction with this facet to the course. They welcome the interaction with their peers, and appreciate the practical approach to learning about engineering disciplines.
\end{abstract}

\section{Introduction}

The University of Dayton (UD) Department of Engineering Technology currently has four programs accredited by the Technology Accreditation Commission of the Accreditation Board for Engineering and Technology (TAC of ABET), and a relatively new program in Computer Engineering Technology is scheduled to undergo its initial accreditation review during the next 
departmental visit. Students pursuing a degree in engineering technology at the University of Dayton have the option of entering the Department of Engineering Technology enrolled in one of the five majors: Computer (CET); Electronic (EET), Industrial (IET), Manufacturing (MFG); or Mechanical (MCT). During their first semester, they begin taking a cadre of classes leading to graduation in their area of interest. A growing number of students, however, know they want to pursue a technical career, but are undecided about which direction to follow. These students enroll in Undeclared Engineering Technology (UET), allowing them to take classes in a variety of disciplines within the department. This growing population needs to be exposed to all of the possible career paths available in order to make an educated decision about their future.

To increase student retention in the Department of Engineering Technology, and to give students a better sense of the field, faculty developed the Engineering Technology First Year Seminar in the late $1950 \mathrm{~s}^{1}$. The course has undergone significant revision ${ }^{2}$ in the past four years to accommodate new learning paradigms and incorporate the University's enrollment requirement for all students to purchase notebook computers. All Engineering Technology students enroll in the course during their first semester at the University. This one-credit course meets for one 75minute class period per week, and is graded on a pass/no credit $(\mathrm{P} / \mathrm{NC})$ basis. Because of this grading scheme, some students realize that attendance and a minimum amount of work are all that are required to obtain credit for the course. As such, engaging students in each area of study is the best way to maintain their interest in the subject area.

Areas of study in the beginning of the course involve discussion and activities related to ethics, diversity, study skills, time management, University policies \& procedures, and the design process. Four weeks of the course, however, are devoted to introducing students to the possible areas of study in Engineering Technology at the University of Dayton. Previously, faculty representatives from each of the Department's disciplines did a "guest lecture" to introduce the majors. The content of each discussion was very instructor-dependent, and varied in style from lecture to demonstration.

Today, the concept of a "unifying theme" outlined by Hedrick ${ }^{3}$ is used to create continuity between the disciplines. The concept of a simple device, the switch, introduces the interdisciplinary nature of the engineering technology disciplines, demonstrating the fact that the same device can be investigated from multiple points of view. Faculty from each of the department's disciplines continue to present the modules, giving students the benefit of meeting some of the faculty they will encounter later in their curriculum.

\section{Module 1: Electronic Engineering Technology}

At the beginning of the session, students are presented with material relating to common circuit control devices: switches, solenoids and relays. The discussion then focuses on the switch where some of the more common configurations are presented such as single-pole single-throw (SPST), single-pole double-throw (SPDT), etc. Students are subsequently introduced for the first time to the digital miltimeter (DMM) where the concept of measuring continuity is demonstrated. 
The final exercise places groups of 2-3 students at each lab bench to figure out the schematic of a switch. Each group is given a different device, and asked to perform a number of tasks. First, they are to make a sketch of the switch indicating the electrical contacts and the "mechanical" switching action. They then use the DMM to determine the electrical configuration of their switch, and make a sketch of the schematic. Finally, based on the physical properties and electrical configuration of their team's switch, the members brainstorm at least ten (10) possible applications for their switch. An example of one student's work can be seen in Figure 1.

Upon complete of the task, each group selects a spokesperson to present their switch configuration and possible applications to the class for further discussion. Ultimately, students recognize that the same electrical configuration is apparent in different packages.

This module addresses department and ABET TC2K outcomes related to critical thinking, working in interdisciplinary teams, and technical presentations.

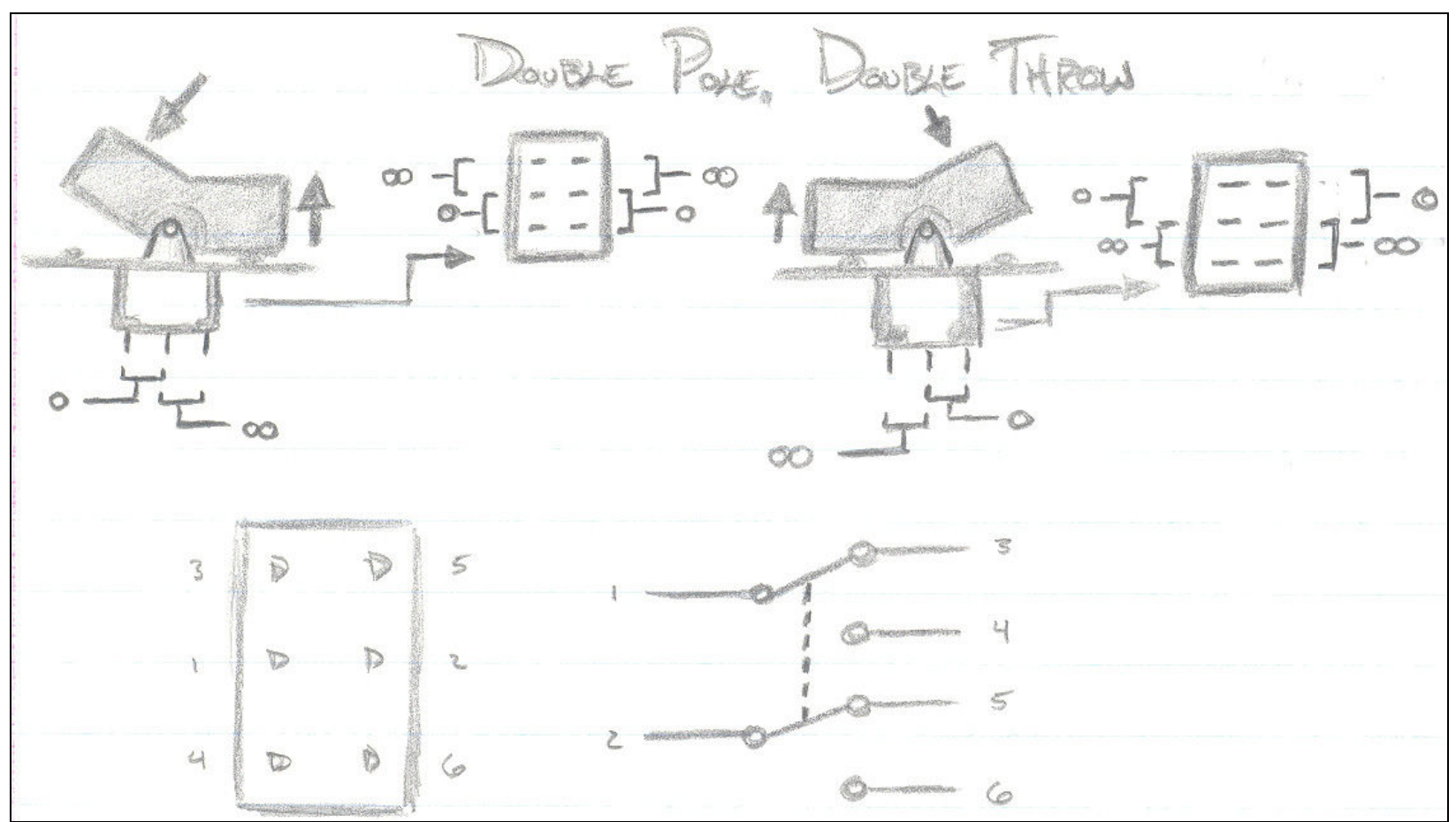

Figure 1. Sample of student work in the Electronic Engineering Technology Module

\section{Module 2: Mechanical Engineering Technology}

In the second module, students review the design process presented earlier in the semester. They then work in pairs, following the steps in the design process, to develop a concept and design for a particular switch. Each group is assigned a specific type of switch such as a refrigerator light switch, a water level switch for a sump pump, a window security alarm switch, etc. In the first step of the exercise, each group is asked to develop the functional requirements for their particular device. 
Further discussion of the design process leads each group through the conceptual design phase where they brainstorm concepts or ideas for their switch. After more instructor-lead group discussion, their final tasks is to take one of their ideas and produce a concept drawing, including the mechanical details (spring action, catch, snap, pivot pin, etc.) for their team's switch. An example of one student's work can be seen in Figure 2.

Finally, one member of the group presents their design to the class for critique and discussion. Students learn and experience the specification and conceptual design phases of the product realization process.

This module addresses department and ABET TC2K outcomes related to critical thinking, working in interdisciplinary teams, creativity in design, and technical presentations.

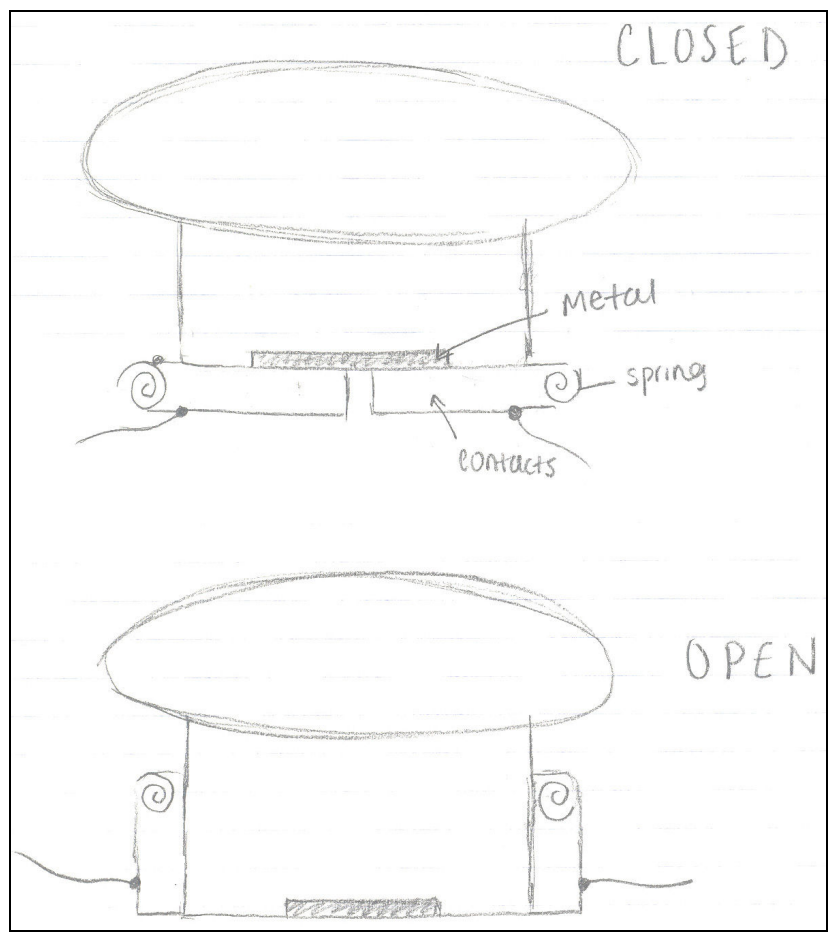

Figure 2. Sample of student work in the Mechanical Engineering Technology Module

\section{Module 3: Manufacturing Engineering Technology}

In module 3, students are introduced to manufacturing materials and processes. This module, adapted from an Introduction to Engineering Technology lab at the University of Southern Colorado ${ }^{4}$, uses identical $120 \mathrm{Vac}$ switches for each team. Groups first create a 3 -view sketch of their device, labeling as many of the parts as possible. They are then asked to carefully disassemble their devices, and create an exploded view sketch as the pieces are removed. Once all of the pieces are labeled, students complete an expanded "bill of materials" indicating a description of each of the parts, the type of material, and the manufacturing process used to make the part. Materials such as plastic (thermoplastic, thermoset), steel, and rubber, and manufacturing processes including stamping, injection molding, and plating are discussed. 
Finally, students use their own assembly drawings to reconstruct the $20+$ pieces into a working device. Students learn about some of the materials and manufacturing processes they will encounter later in the curriculum, but also discover the importance of proper documentation of their work. Figure 3 shows an example of one student's work in this area.

This module addresses department and $\mathrm{ABET} \mathrm{TC} 2 \mathrm{~K}$ outcomes related to critical thinking, and working in interdisciplinary teams.

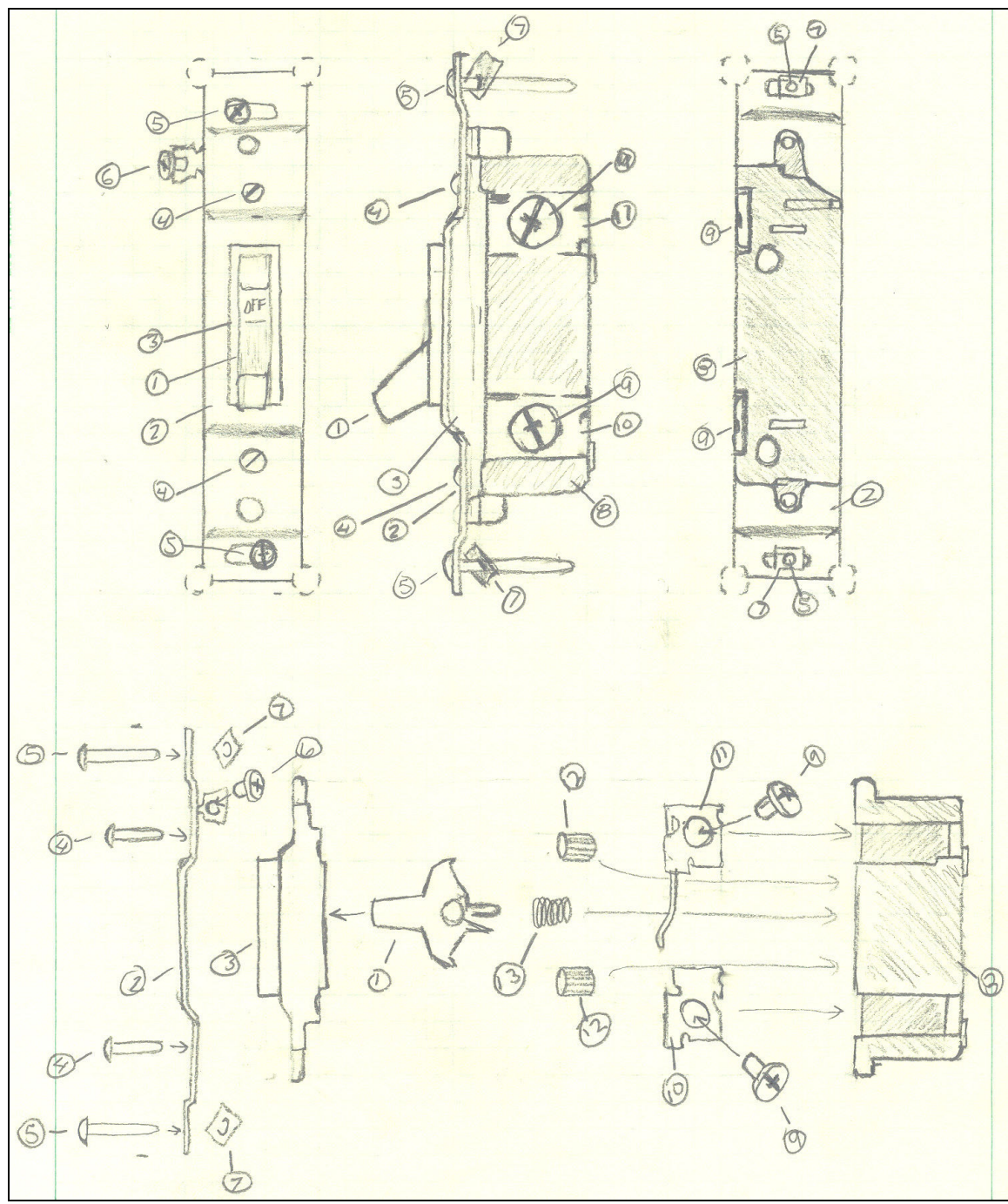

Figure 3. Sample of student work in the Manufacturing Engineering Technology Module 


\section{Module 4: Industrial Engineering Technology}

The final module introduces students to the Industrial Engineering Technology concepts of cost, productivity, and quality. Teams of students are given enough switch parts to assemble three complete switches. Without much direction or discussion, the teams are asked to use their own assembly drawings from the previous week's activity to assemble complete switches. Each team's time to complete the assembly of all of their switches is recorded.

Students are next asked to brainstorm methods to make their assembly process more efficient. Such ideas as organizing parts, assigning specific tasks to team members, and simple fixtures are discussed. The teams are then given time to set-up their manufacturing work cell, and discuss their method for producing their product. Once again, the teams are timed on their ability to complete the task, which usually results in a considerably quicker assembly time.

A discussion of cost relating to time and salary, and overall productivity is introduced. Teams then calculate how their increase in production efficiency for a simple task can be related to annual cost savings. Students learn about basic concepts of work measurement, productivity, cost, and quality, which will form the basis of future coursework in Industrial Engineering Technology.

This module addresses department and ABET TC2K outcomes related to critical thinking, working in interdisciplinary teams, and creativity in design.

\section{Results}

In addition to the standard University of Dayton student assessment, students enrolled in the course were asked to complete an anonymous survey relating to their fist-year experience in the Department of Engineering Technology. The survey was administered via the course WebCT site to all 41 students enrolled in both sections of the course. Thirty-five students $(85 \%)$ students completed the survey. In the twenty (20) question survey, three (3) of the questions related to the Introduction to Engineering Technology modules:

5. My first semester at UD helped me to understand the field of engineering technology I intend to pursue, or how to select a major if I do not have one yet.

14. My first semester at UD helped me to develop a basic understanding of engineering design principles.

17. My fist semester at UD helped me to understand team dynamics and the value of working on teams.

Table 1 is an excerpt from the analysis of the survey related to the course outcomes for the Fall 2003 semester. 
Table 1. Survey Questions Related To Course Outcomes

\begin{tabular}{|c|c|c|c|}
\hline $\begin{array}{l}\text { Upon completion of this course the student } \\
\text { will: }\end{array}$ & $\begin{array}{c}\text { Survey } \\
\text { Questions }\end{array}$ & Target & Actual \\
\hline $\begin{array}{l}\text { 3. have an understanding of learning } \\
\text { through working in groups and teams }\end{array}$ & 17 & \multirow{3}{*}{$\begin{array}{l}>80 \% \text { of } \\
\text { students } \\
\text { "Agree" or } \\
\text { "Strongly } \\
\text { Agree" }\end{array}$} & $\begin{array}{c}\text { 9/35 Strongly Agree } \\
\text { 21/35 Agree } \\
\mathbf{8 6 \%} \\
\end{array}$ \\
\hline $\begin{array}{l}\text { 5. have an understanding of educational } \\
\text { expectations and careers in } \\
\text { engineering technology }\end{array}$ & 5 & & $\begin{array}{c}\text { 9/35 Strongly Agree } \\
\text { 19/35 Agree } \\
\mathbf{8 0 \%}\end{array}$ \\
\hline $\begin{array}{l}\text { 7. have a rudimentary understanding of } \\
\text { the design process }\end{array}$ & 14 & & $\begin{array}{c}\text { 7/35 Strongly Agree } \\
\text { 24/35 Agree } \\
\mathbf{8 9 \%}\end{array}$ \\
\hline
\end{tabular}

The survey also asked three (3) open-ended questions relating to "areas you found particularly helpful," "elements that need improvement," and "additional comments." Six (6) students indicated a positive response to the modules introducing the areas of engineering technology, while there was only one negative response requesting more "depth" to the modules. Under "additional comments," there were four (4) responses suggesting that the modules be expanded to provide more depth over a greater period of time within the course.

\section{Conclusions}

The University of Dayton's approach to introducing students to the multidisciplinary aspects of engineering technology increases their interest and awareness of potential programs of study. Faculty observe that students are engaged in the learning process, and the analysis of course outcomes indicates that students are satisfied with their exposure to the fields of engineering technology, the design process, and working in groups and teams. This course fulfills its objective of exposing students to the Department offerings while laying the foundation for future work in engineering technology.

The hands-on approach to introducing the technical disciplines engages the students in the learning process, and makes a lasting impression of the concepts discussed. Introducing a unifying theme to the technical modules creates continuity between the disciplines and assists students in understanding that their area of study will indeed integrate diverse technical fields.

\section{Acknowledgements}

Special thanks to University of Dayton Department of Engineering Technology faculty Chuck Edmonson, Jim Globig, Dave Myszka, and Bob Wolff for their work in developing and delivering the Introduction to Engineering Technology modules discussed in this paper. 


\section{References}

1. University of Dayton Bulletin 1959-60. Volume 70, Number 2. February, 1959.

2. Segalewitz, S. A Paperless Engineering Technology First-Year Seminar Course Emphasizing Critical Thinking, Communication, and Teamwork. Proceedings of the 2002 American Society for Engineering Education Annual Conference \& Exposition. 2002.

3. Hedrick, J. Maintaining Quality and Student Enthusiasm in a Freshman Engineering Course. Proceedings of the 2001 American Society for Engineering Education Annual Conference \& Exposition. 2002

4. University of Southern Colorado. Introduction to Engineering Technology. [Web] ceeps.uscolo.edu

SCOTT SEGALEWITZ is Associate Professor and Chair of Engineering Technology at the University of Dayton. He earned an MS in Biomedical Engineering from New Jersey Institute of Technology, a BSEE from Rutgers University, and is a licensed Professional Engineer. His areas of interest include distance and asynchronous learning, technical communications, technology in education, and continuous improvement in the learning environment. 